\title{
ANÁLISE DE CORRELAÇÃO ENTRE O INVESTIMENTO PER CAPITA EM ENSINO FUNDAMENTAL REGULAR EOS RESULTADOS ANUAIS DO IDEB DOS MUNIĆ́PIOS DE SANTA CATA- RINA E REGIONALIZAÇÕES DA FECAM PARA OS ANOS DE 2005 A 2011*
}

ANALYSIS OF THE CORRELATION BETWEEN THE INVESTMENT PER CAPITA IN REGULAR ELEMENTARY SCHOOL'S AND ANNUAL RESULTS OF IDEB OF THE MUNICIPALITIES IN SANTA CATARINA STATE AND REGIONALISATIONS OF FECAM FOR THE YEARS FROM 2005 TO 2011

\section{Márcio Luft** \\ Mestre em Políticas Sociais e Dinâmicas Regionais - UNOCHAPECÓ | Brasil E-mail: marcioluft1706@gmail.com}

Leonel Piovezana*** Doutor em Desenvolvimento Regional - UNISC | Brasil Email: leonel@unochapeco.edu.br

REVISTA PEDAGÓGICA

Revista do Programa de Pós-graduação em Educação da Unochapecó | ISSN 1984-1566 Universidade Comunitária da Região de Chapecó | Chapecó-SC, Brasil

Como referenciar este artigo: LUFT, M. PIOVEZANA, L. Análises de correlação entre o investsimento per capita em ensino fundamental regular e os resultados anuais do IDEB dos municípios de Santa Catarina e Regionalizações da FECAM para os anos de 2005 a 2011. Revista Pedagógica, Chapecó, v.15, n.31, p. 367-388, jul./dez. 2013.

RESUMO: O artigo apresenta resultados derivados de análise quantitativa de correlação entre o investimento per capita em Ensino Fundamental Regular e os resultados anuais do IDEB dos 293 municípios de Santa Catarina para os anos de 2005 a 2011, efetuadas a partir do cruzamento de três naturezas distintas: 01-financeiros: relativos ao investimento em ensino fundamental trazidos ao valor presente de 2011 pelo índice IGP-DI, 02-demográficos estudantis: relativos ao quantitativo de matrículas em cada um dos anos citados para os dois níveis (séries iniciais e finais) e o3-desempenho: por meio do IDEB; obtendo resultados a partir de três segmentações: o1-população: a partir do número de habitantes do município para cada ano, 02-por ano: isolando os dados em grupos conforme o ano de origem e o3-por regionalismo geopolítico: a partir da divisão formal apresentada pela FECAM. A busca do índice per capita foi necessária para igualar os municípios em uma base comum, evitando que valores absolutos, baseados apenas no PIB, indiquem, de forma distorcida, a quantidade investida por município, limitada a um olhar estrutural de cima para baixo sem considerar a demografia atingida. A escolha do Ensino Fundamental se
ABSTRACT:This article presents results derived from quantitative analysis of correlation between the per capita investment in Regular elementary school and annual results of IDEB in 293 municipalities of Santa Catarina state for the period between the years 2005 to 2011, made from the intersection of three distinct natures: 01-financial: related to the investment in elementary school brought to the present value of the year 2011, through IGP-DI inflation index, 02- demographic student: relates to the number of registrations in each of the years referred to the two levels (initial and final series) and o3-performance: through the IDEB; getting results from three segmentations: 01-population: from the number of inhabitants of the municipality for each year, 02-per year: isolating the data into groups according to the year of origin and o3-by geopolitical regionalism: from the formal Division presented by FECAM. The per capita index search was necessary to match the municipalities on a common basis, avoiding absolute values, based only on GDP, indicate, in a distorted way, the amount invested by each municipality, limited to a structural look from top to bottom without considering the demographics hit. 
deu devido à existência de maior quantidade de dados disponíveis e por representar maior peso monetário frente aos demais níveis, representando mais da metade de todo o Investimento Público Direto Municipal em educação em todos os anos contemplados pela pesquisa. Dentro do universo pesquisado houve incompletude em alguns dos indicadores, o que inviabilizou a análise integral por depender de todas as informações de todas as naturezas para um ano/município ser validado, isso reduziu o número de dados utilizáveis para $75,48 \%$ das séries iniciais e apenas $38,37 \%$ das séries finais, que em valores absolutos, somando os dois níveis, resultou no montante de $\mathrm{R} \$ 11.238 .416 .963,59$ de um total de $\mathrm{R} \$$ 12.344.632.409,01; o que representa 91,04\% do total do Valor Financeiro contemplado pelo universo escolhido. Conclui que não houve relação estatística significativa entre Investimentos Públicos Diretos Municipais e IDEB na Educação Básica dos municípios de Santa Catarina no período de 2005 a 2011.

PALAVRAS-CHAVE: FECAM, IDEB, Investimento Público.
The Elementary school choice was because of the greater amount of available data and represent greater monetary weight front to the other levels representing more than half of all Direct Municipal public investment in Education in all the years covered by the survey. Inside the researched universe there was incompleteness in some of the indicators, which impeded the full analysis by relying on all information of all natures for a year/municipality be validated, this fact reduced the number of usable data to $75.48 \%$ of the initial series and only $38.37 \%$ of final series, which in absolute values, adding the two levels, resulted in the amount of $\mathrm{R} \$ 11.238 .416 .963,59$ out of a total of R $\$ 12.344 .632 .409,01$; that represents 91.04\% of the total financial value contemplated by the chosen universe. Concludes that there wasn't statistically significant between Direct Municipal public investment and IDEB in Basic Education in the municipalities of Santa Catarina state during the period from 2005 to 2011.

KEYWORDS: FECAM, IDEB, Public Investment. 
*Este artigo deriva da dissertação de mesmo título defendida em 2013, junto ao Programa de Pós-graduação em Políticas Sociais e Dinâmicas Regionais da UNOCHAPECÓ.

** Mestre em Políticas Sociais e Dinâmicas Regionais (UNOCHAPECÓ). Técnico-administrativo em Educação, na Universidade Federal da Fronteira Sul (UFFS). Professor no Centro de Ensino Superior Santa Rita Ltda-Me e na Faculdade Regional Palmitos. E-mail: marcioluft1706@gmail.com.

*** Doutor em Desenvolvimento Regional (UNISC). Professor do Programa de Pós-graduação em Educação e do Programa de Pós-graduação em Políticas Sociais e Dinâmicas Regionais, ambos da UNOCHAPECÓ. E-mail: leonel@unochapeco.edu.br

\section{INTRODUÇÃO}

A educação, por sua importância social, motiva extensos debates quanto à qualidade, investimentos, indicadores e outros. Historicamente política faz uso dos dados de investimento em educação em discursos que pretendem demonstrar não apenas o compromisso público, mas também a valorização dada a esta área. Existem prescrições legais que definem o quantitativo mínimo que um município deve investir em educação, mas os montantes são definidos a partir valores absolutos relacionados à arrecadação do município e não ao quantitativo de alunos matriculados. O presente estudo trabalhou com dados financeiros, demográficos e índices de rendimento do Ensino Fundamental Regular - EFR de todos os municípios de Santa Catarina (293) dos anos de 2005 a 2011 de modo quantitativo, o qual se justifica pelo grande volume de dados delimitados para o estudo.

O desenvolvimento percorreu pressupostos de legalidade e objetividade, ao passo que não investigou hipóteses que motivam as variações de dados ou mesmo sua inexistência, apenas constatou; e a partir do método quantitativo realizou a busca de correlação estatística entre os dados monetários de investimento per capita em Ensino Fundamental Regular frente ao IDEB apresentado pelo INEP que mede o desempenho da Educação Básica nacional. O estudo contemplou todo o estado de Santa Catarina e considerou os regionalismos geopolíticos formais da FECAM para fins de criação de índices-padrão que permitiram comparativos estatísticos entre regiões e responderam a seguinte pergunta: Os investimentos per capita em educação (total do investimento em Ensino Fundamental Regular por ano dividido pelo seu total de matrículas do mesmo ano) possuem alguma relação estatística com os resultados anuais apresentados pelo Índice de Desenvolvimento da educação Básica - IDEB dos municípios de Santa Catarina e regionalizações da FECAM para os anos de 2005 a 2011? De modo objetivo: Municípios que investem mais em Ensino Fundamental Regular obtêm maiores notas no IDEB?

Para tanto se fez necessária a realização de uma análise de correlação entre os dados buscando identificar o grau de normalidade da relação "resultado / investimento" para cada município e cada região em cada ano pesquisado, evidenciando o grau de disparidade daqueles que não se enquadraram no universo da normalidade estudada à qual pertencem. Foi possível a constatação estatística de índices-padrão para os municípios, seus regionalismos (FECAM) e para o estado de Santa Catarina. O estudo aceita que existam outras variáveis que possam influenciar no desempenho de um município em determinado ano como políticas públicas de qualquer das esferas ou mesmo a sociedade organizada, no entanto o recurso financeiro detém representatividade significativa no processo de operacio- 
nalização da educação; assim, considerando o volume de dados, foi possível apresentar o que há em comum nos índices de gestão dos recursos municipais em Ensino Fundamental Regular, o que permitiu avançar em um posicionamento científico mais voltado para geração bases de dados para futuras pesquisas qualitativas ao passo que respondia ao seu objetivo. Ao findar das análises foi possível identificar de formas direta e segmentada: a) Os municípios com maior e menor investimento per capita. b) Os municípios com maior e menor resultado no IDEB. c) O quanto custou, em valor monetário, cada ponto no IDEB por município, por região da FECAM e do Estado de Santa Catarina e seus respectivos valores médios. d) A relação entre IDEB e Investimento per capita com segmentações baseadas em população dos municípios, ano dos dados e associações político-regionais da FECAM. Ao considerar (BRASIL, 1996), os governos municipais são obrigados, por força da Lei $\mathrm{N}^{\circ}$ 9.394, de 20 de dezembro de 1996, em seu artigo 69 (que estabelece as diretrizes e bases da educação nacional), a investir 25\% (vinte e cinco por cento); ou o que consta nas respectivas Constituições ou Leis Orgânicas (se percentual maior) da receita resultante de impostos, compreendidas as transferências constitucionais, na manutenção e desenvolvimento do ensino público. Este formato de investimento demonstra um posicionamento "de cima para baixo", teorizado e aplicado em 1916 por Henri Fayol na chamada Teoria Clássica da Administração. O estudo não propõe mudança ao modelo atual, nem mesmo critica sua eficácia, no entanto sugere reflexões sobre o impacto desse modelo aos indivíduos que dependem dele para o alcance de sua formação com qualidade.

A lei supracitada indica que o montante a ser destinado ao EFR não considera o número de alunos sob a responsabilidade do município, mas sim a arrecadação municipal e seu status populacional, ignorando que as taxas de natalidade passam por significativas oscilações de um município para outro, seja por sua cultura, localização geográfica, quantitativo populacional, incentivos públicos, Índice de Desenvolvimento Humano - IDH, dentre outros.

Verificar o montante per capita representa saber o investimento municipal real a partir do posicionamento do aluno "de baixo para cima", esta ideia está representada na seguinte metáfora desenvolvida pelo pesquisador:

Hipoteticamente será feita uma comparação de destinação de recursos para alimentação de crianças em dois municípios imaginários. Imagine que uma lei federal obrigasse os municípios a investir pelo menos $15 \%$ de sua receita anual para a alimentação de crianças. Imagine que o município "A" possui grande população e investe 30\% de sua receita anual (o dobro do que a lei obriga) em alimentação infantil, que transformado em pães (por exemplo) representaria 100 unidades. Imagine que o mu- 
nicípio "B" possui uma população pequena e investe apenas 15\% de sua receita anual (obrigação legal) em alimentação infantil, o que representaria 10 unidades de pães. Diante da circunstância o município "A" poderia afirmar que investe o dobro do município "B" e ainda que seu investimento, em valores absolutos, chega a ser dez vezes maior. No entanto se o município "A" tiver 200 alunos e o município "B" tiver 05 alunos, a percepção do mesmo dado tem diferente significado, pois ao final cada aluno do município "A" receberia meio pão, enquanto os do município "B" receberiam dois, conforme tabela ilustrativa:

Tabela 01: Hipótese de investimento per capita em alimentação.

\begin{tabular}{|c|c|c|c|c|}
\hline $\begin{array}{c}\text { MUNICÍ- } \\
\text { PIO }\end{array}$ & $\begin{array}{c}\text { Per- } \\
\text { centual } \\
\text { sobre a } \\
\text { receita }\end{array}$ & $\begin{array}{c}\text { Recur- } \\
\text { so em } \\
\text { pães }\end{array}$ & $\begin{array}{c}\text { Número } \\
\text { de alu- } \\
\text { nos }\end{array}$ & $\begin{array}{c}\text { Quantida- } \\
\text { de de pães } \\
\text { por aluno }\end{array}$ \\
\hline “A" & $30 \%$ & 100 & 200 & 0,5 \\
\hline "B" & $15 \%$ & 10 & 05 & 02 \\
\hline \multicolumn{4}{|l}{ Fonte: Luft (2013). }
\end{tabular}

O equilíbrio ideal seria o uso de um posicionamento "de baixo para cima" a fim de que cada aluno de ambas as cidades recebesse um pão, evitando excessos e escassez. Essa representação busca demonstrar que o discurso quanto ao tamanho do investimento de um município em educação não pode amparar-se apenas em comparativos absolutos frente a outros municípios ou com os montantes investidos em outras áreas, comparado com o montante gasto em educação; ou ainda se resguardar apenas em preceitos legais para comprovar que atende o mínimo obrigatório prescrito em lei. Obviamente diferentes municípios possuem diferentes obstáculos para o cumprimento de seus deveres junto à educação, mas evoca-se a reflexão quanto aos parâmetros utilizados na definição dos montantes destinados ao Ensino Fundamental Regular e se isso impacta nos resultados anuais apresentados pelo Índice de Desenvolvimento da educação Básica - IDEB. O estudo ampara-se em três grandes fontes de dados obtidas em sítios eletrônicos oficiais: 01-O quando se gastou em EFR? Denominado: "Investimentos em Educação Básica por Município"; 02-Quantos utilizaram o sistema de EFR? Denominado: "Demografia da Educação Básica por Município" e 03-Qual o desempenho do sistema de EFR? Denominado: "Índice de Desenvolvimento da Educação Básica por Município".

\section{REPRESENTATIVIDADE DOS DADOS E IDENTIFICAÇÃO DO UNIVERSO}

Identificar a representatividade de um investimento em determinada área, permitiu ao pesquisador saber se os esforços dedicados iriam impactar em algo financeiramente significativo às contas públicas. 
Tabela 02: Percentual de Investimento Público Direto Municipal em Educação em relação ao PIB por Nível de Ensino.

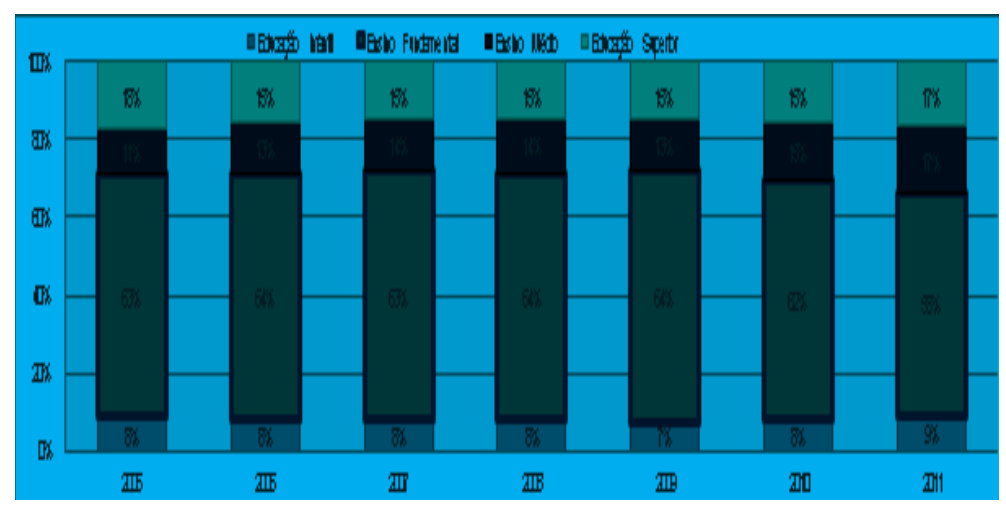

Fonte: Elaborado pelo pesquisador. INEP, 2011j.

Em todos os anos, contemplados pelo estudo, os Investimentos Públicos Diretos Municipais em Ensino Fundamental Regular superou em mais da metade os investimentos nas outras áreas.

A pesquisa demandou de seis naturezas de dados distintas: 01 - 2.051 dados Financeiros (Tesouro Nacional), para saber quanto foi gasto. (293 municípios x 07 anos); 02 - 06 dados Econômicos (FGV-IBRE), para tornar os valores equivalentes frente ao tempo para atualização monetária dos valores óbitos em data anterior a 2011. (o6 anos); 03 - 4.102 dados Demográficos Educacionais (INEP), para saber quantos foram beneficiados. (293 municípios x 07 anos x 02 tipos: " $1{ }^{\mathrm{a}}-4$ " e " 5 a -8 "); 04 - 2.051 dados Populacionais Municipais (Tesouro Nacional/IBGE), para identificar grandes centros de pequenos municípios. (293 municípios x 07 anos); 05 - 293 dados Político-Regionais (FECAM), para verificar se este regionalismo influencia os resultados. (293 municípios); 06 - 2.344 dados de Desempenho (INEP/IDEB), para identificar os municípios que detém melhores resultados. Obs.: O IDEB é medido a cada dois anos obtiveram-se dados de 2005, 2007, 2009 e 2011; para 2006, 2008 e 2010 foi gerada uma média intermediária para fins de cálculo. (293 municípios x 04 anos x 02 tipos: " $1^{\mathrm{a}}-4^{\mathrm{a}}$ " e " $5^{\mathrm{a}}-8^{\mathrm{a}}$ "). Dados Totais: 10.848.

Para obtenção de um indicador final, faz-se necessária a existência de dados de todas as naturezas para cada município em cada ano, a falta de qualquer dado em alguma das naturezas inviabiliza a análise para aquele município naquele ano. Graficamente pode-se observar que o banco de dados obtido possui algumas lacunas significativas, principalmente em relação aos anos finais $\left(5^{\mathrm{a}}\right.$ a $8^{\mathrm{a}}$ séries), afetando a completude. 
Gráfico o1: Percentual de dados acumulados de 2005 a 2011, obtidos sobre o universo pesquisado para Todas as Naturezas.

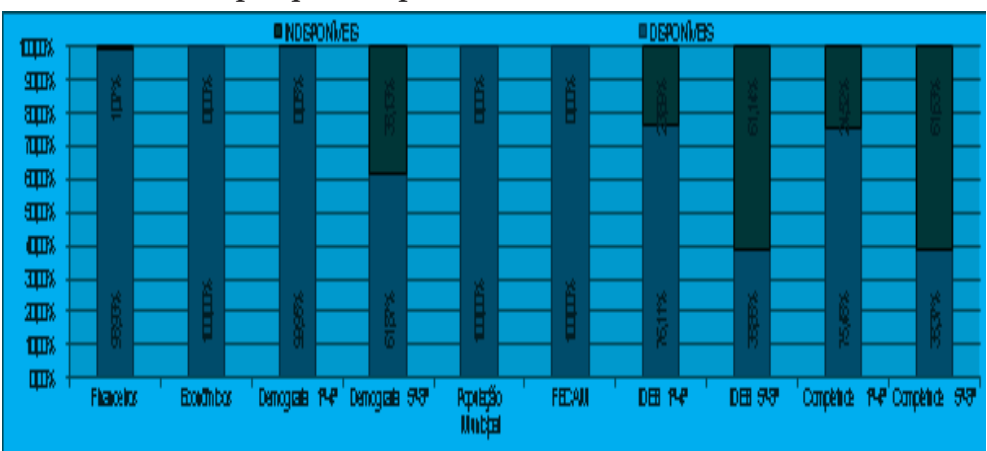

Fonte: Desenvolvido pelo pesquisador. Tesouro Nacional, 2011a, 2011b, 2011c, 2011d, 2011e, 2011f, 2011g; FGV-IBRE, 2009; INEP, 2011d; FECAM, 2013c e INEP, 2011f e 2011g.

Outro fator que desafia o pesquisador está na necessidade em saber qual a representatividade destes dados dentro do universo escolhido, demonstrado na tabela a seguir:

Tabela 3: Representatividade da completude em termos monetários.

\begin{tabular}{|c|c|c|c|c|c|}
\hline ANO & $\begin{array}{c}\text { Disponível } \\
\left(1^{\mathrm{a}} \mathbf{a}^{\mathrm{a}}\right)\end{array}$ & $\begin{array}{c}\text { Indisponível } \\
\left(1^{\mathrm{a}} a 4^{\mathrm{a}}\right)\end{array}$ & $\begin{array}{c}\text { Disponível } \\
\left.5^{\mathrm{a}} \text { a } 8^{\mathrm{a}}\right)\end{array}$ & $\begin{array}{c}\text { Indisponível } \\
\left(5^{\mathrm{a}} \text { a } 8^{\mathrm{a}}\right)\end{array}$ & TOTAIS \\
\hline 2005 & $810.107 .508,28$ & $118.057 .768,85$ & $430.282 .599,66$ & $58.492 .199,10$ & $1.416 .940 .075,89$ \\
\hline 2006 & $875.139 .840,75$ & $130.657 .726,22$ & $450.072 .924,99$ & $62.286 .747,87$ & $1.518 .157 \cdot 239,83$ \\
\hline 2007 & $986.937 .042,86$ & $83.519 .368,56$ & $522.793 .033,62$ & $47.875 .829,61$ & $1.641 .125 \cdot 274,65$ \\
\hline 2008 & $1.056 .707 .628,86$ & $88.935 \cdot 317,00$ & $586.019 .551,92$ & $49.261 .646,03$ & $1.780 .924 .143,81$ \\
\hline 2009 & $1.155 \cdot 156.271,14$ & $79 \cdot 493 \cdot 575,39$ & $666.901 .241,83$ & $51.131 .911,85$ & $1.952 .683 .000,21$ \\
\hline 2010 & $1.067 .890 .167,24$ & $123.648 .213,64$ & $683.308 .640,62$ & $63.486 .027,99$ & $1.938 .333 .049,49$ \\
\hline 2011 & $1.258 .125 .053,64$ & 98.611.052,22 & $688.975 \cdot 458,18$ & $50.758 .051,05$ & $2.096 .469 .615,10$ \\
\hline $\begin{array}{c}\text { TO- } \\
\text { TAIS }\end{array}$ & $7.210 .063 \cdot 512,77$ & $722.551 \cdot 332,38$ & $4.028 .353 .450,82$ & $382.920 .724,00$ & $12.343 .889 .019,98$ \\
\hline
\end{tabular}

Fonte: Desenvolvido pelo pesquisador. Tesouro Nacional, 2011a, 2011b, 2011c, 2011d, 2011e, 2011f, 2011g; FGV-IBRE, 2009; INEP, 2011d; FECAM, 2013c e INEP, 2011f e 2011g.

Os valores acima somados diferem do total somado em $\mathrm{R}$ \$ 10,04 em função de arredondamentos necessários para o cálculo do investimento per capita, não representando significância dentro deste universo. Importante rememorar que para os anos de 2006, 2008 e 2010 foram geradas médias intermediárias para os dados do IDEB, as quais dependiam de dados do ano anterior e do ano posterior, isso significa que na falta de um deles a média não podia ser gerada, assim esses anos dependem da existência combinada dos dados de ambos os anos: anterior e posterior. A seguir o gráfico representativo percentual da tabela anterior.

Gráfico o2: Representatividade monetária percentual da completude de dados do Ensino Fundamental ( $1^{\mathrm{a}}$ a $4^{\mathrm{a}}$ séries e $5^{\mathrm{a}}$ a $8^{\mathrm{a}}$ séries), fracionados por ano.

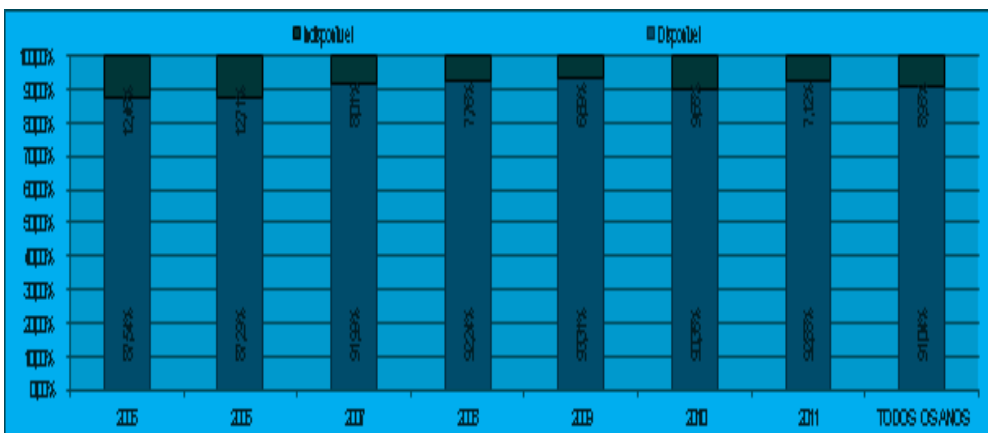

Fonte: Desenvolvido pelo pesquisador. Tesouro Nacional, 2011a, 2011b, 2011c, 2011d, 2011e, 2011f, 2011g; FGV-IBRE, 2009; INEP, 2011d; FECAM, 2013c e INEP, 2011f e 2011g. 
Apesar de dispor de 75,48\% dos dados completos para as séries iniciais e apenas $38,37 \%$ dos dados completos para as séries finais, em termos de valor investido, somados eles representam 91,04\% do total de Investimento Públicos Diretos Municipais em Ensino Fundamental Regular para os municípios de Santa Catarina no período de 2005 a 2011, dando maior confiabilidade nas conclusões em função da representatividade.

\section{IDEB MÉDIO SEGMENTADO POR POPULAÇÃO}

Esta análise identificou onde o IDEB médio dos anos de 2005 a 2011 foi maior, segmentando os resultados a partir do quantitativo populacional. Os resultados para as séries iniciais foram: até 5.00o hab. 4,99; de 5.001 a 10.00o hab. 4,87; de 10.001 a 50.000 hab. 4,86 ; de 50.001 a 100.000 hab. 4,76; acima de 100.000 hab. 4,98 .

Cidades com menos habitantes detém a maior média do IDEB para os anos de 2005 a 2011, nas séries iniciais, fato que não se repetiu para os anos finais sobre os resultados dos municípios mais populosos. Os resultados foram: até 5.00o hab. 4,59; de 5.001 a 10.000 hab. 4,28; de 10.001 a 50.000 hab. 4,33 ; de 50.001 a 100.000 hab. 4,26; acima de 100.00o hab. 4,31.

\section{IDEB X INVESTIMENTO PER CAPITA SEG- MENTADO PELA POPULAÇÃO}

Relacionar IDEB com investimento per capita permite obter informações sobre uma das questões mais polêmicas no ao se falar em qualidade no ensino: quanto se deve investir em educação para obter resultados de desempenho? A tabela a seguir apresenta as médias de investimento per capita e IDEB para os municípios de Santa Catarina para os anos iniciais:

Tabela 04: Médias do IDEB e do Investimento per capita para as séries iniciais de 2005 a 2011, segmentadas por população. (em R $\$$ )

\begin{tabular}{|c|c|c|c|c|c|}
\hline $\begin{array}{c}\text { Seg- } \\
\text { menta- } \\
\text { ção }\end{array}$ & $\begin{array}{c}\text { Até } \\
5.000\end{array}$ & $\begin{array}{c}\text { De } \\
5.001 \\
\text { a } \\
10.000\end{array}$ & $\begin{array}{c}\text { De } \\
10.001 \\
\text { a } \\
50.000\end{array}$ & $\begin{array}{c}\text { De } \\
\mathbf{5 0 . 0 0 1} \\
\text { a } \\
100.000\end{array}$ & $\begin{array}{c}\text { Acima } \\
\text { de } \\
\text { 100.000 }\end{array}$ \\
\hline $\begin{array}{l}\text { Média: } \\
\text { Investi- } \\
\text { mento } \\
\text { Per Ca- } \\
\text { pita }\end{array}$ & 7827,15 & 5572,93 & 4475,94 & 3954,36 & 41043,73 \\
\hline $\begin{array}{l}\text { Média: } \\
\text { IDEB }\end{array}$ & 4,99 & 4,87 & 4,86 & 4,76 & 4,98 \\
\hline
\end{tabular}

2011d, 2011e, 2011f, 2011g; FGV-IBRE, 2009; INEP, 2011 e INEP, 2011f e 2011g.

A identificação de correlação depende de um comparativo de mesma base para que se verifique o quanto que um e outro se comportam em cada categoria populacional. O gráfico a seguir permite compreender melhor: 
Gráfico o6: Médias do IDEB e do Investimento per capita para as séries iniciais de 2005 a 2011, segmentadas por população.

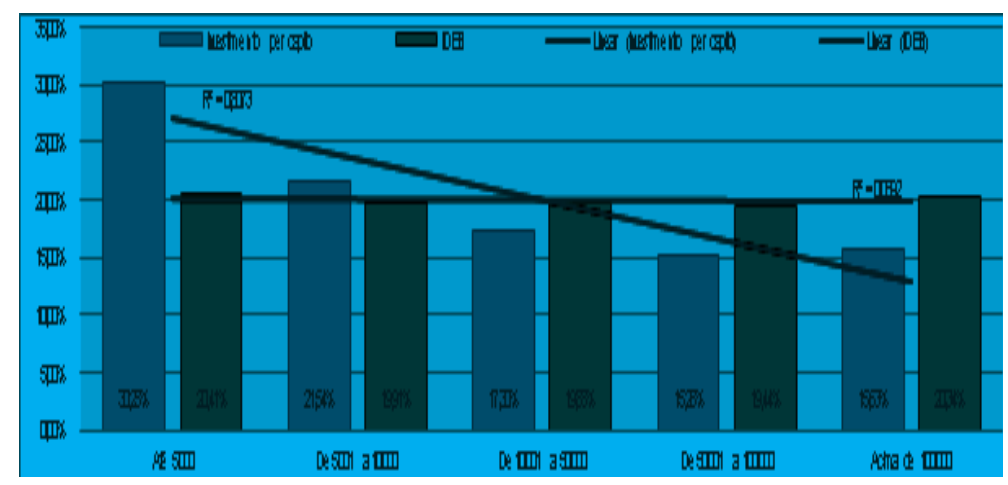

Fonte: Desenvolvido pelo pesquisador. Tesouro Nacional, 2011a, 2011b, 2011c, 2011d, 2011e, 2011f, 2011g; FGV-IBRE, 2009; INEP, 2011 e INEP, 2011f e 2011g.

Logo se percebe que enquanto o investimento per capita mostra-se menos à medida que os municípios crescem, o IDEB permanece quase que inalterado, enquanto o investimento reduziu, dos municípios com até 5.000 habitantes para os de 50.001 a 100.000, 49,48\%, o IDEB reduziu apenas $4,75 \%$.

Tabela o5: Médias do IDEB e do Investimento per capita para as séries finais de 2005 a 2011, segmentadas por população (em R\$).

\begin{tabular}{|l|c|c|c|c|c|}
\hline $\begin{array}{c}\text { Segmen- } \\
\text { tação }\end{array}$ & $\begin{array}{c}\text { Até } \\
\mathbf{5 . 0 0 0}\end{array}$ & $\begin{array}{c}\text { De } \\
\mathbf{5 . 0 0 1} \mathbf{a} \\
\mathbf{1 0 . 0 0 0}\end{array}$ & $\begin{array}{c}\text { De } \\
\mathbf{1 0 . 0 0 1} \mathbf{5 0 . 0 0 0}\end{array}$ & $\begin{array}{c}\text { De } \\
\mathbf{5 0 . 0 0 1} \\
\mathbf{1 0 0 . 0 0 0}\end{array}$ & $\begin{array}{c}\text { Aci- } \\
\text { ma de } \\
\mathbf{1 0 0 . 0 0 0}\end{array}$ \\
\hline $\begin{array}{c}\text { Média: In- } \\
\text { vestimen- } \\
\text { to Per } \\
\text { Capita }\end{array}$ & $6.588,87$ & $4.620,62$ & $4.369,85$ & $3.904,99$ & $4.043,73$ \\
\hline $\begin{array}{c}\text { Média: } \\
\text { IDEB }\end{array}$ & 4,59 & 4,28 & 4,33 & 4,26 & 4,31 \\
\hline
\end{tabular}
2011d, 2011e, 2011f, 2011g; FGV-IBRE, 2009; INEP, 2011 e INEP, 2011f e 2011g.

Segue gráfico contendo a proporção percentual representativa.

Gráfico 07: Médias do IDEB e do Investimento per capita para as séries finais de 2005 a 2011, segmentadas por população.

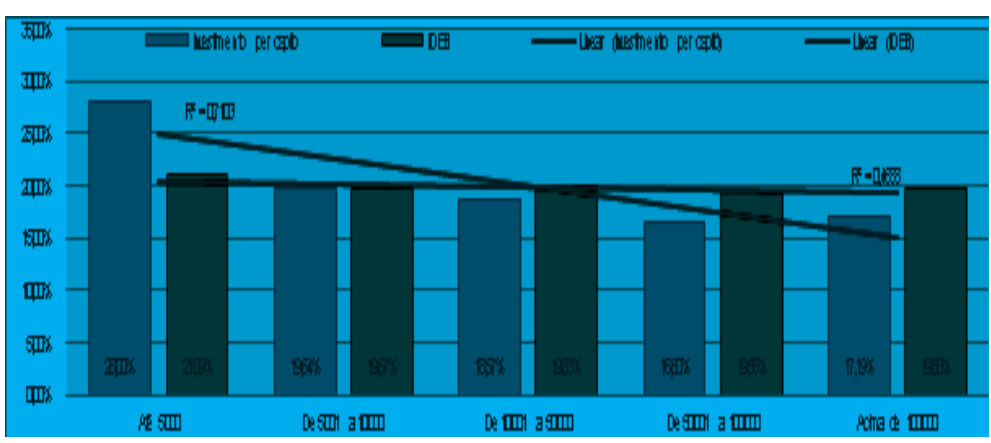

Fonte: Desenvolvido pelo pesquisador. Tesouro Nacional, 2011a, 2011b, 2011c, 2011d, 2011e, 2011f, 2011g; FGV-IBRE, 2009; INEP, 2011 e INEP, 2011f e 2011g. 
O mesmo se apresenta para as séries finais onde investimento reduziu, dos municípios com até 5.000 habitantes para os de 50.001 a 100.000, 40,73\% enquanto o IDEB reduziu apenas 7,24\%. Estes resultados começam a sinalizar algo importante ao passo que demonstram que o investimento per capita e resultados de desempenho não possui relação significativa, no entanto outras análises irão complementar este raciocínio.

\section{IDEB X INVESTIMENTO PER CAPITA SEG- MENTADO POR ANO}

O entendimento que o tempo influencia resultados se manifestou nesta análise, pois ao cruzar os dados de investimento com os de desempenho considerando o tempo, foi revelada significativa correlação, esta demonstrada nos gráficos a seguir.

Tabela o6: Médias do IDEB e do Investimento per capita para as séries iniciais de 2005 a 2011, segmentadas por ano.

\begin{tabular}{|c|c|c|c|c|c|c|c|}
\hline $\begin{array}{c}\text { Seg- } \\
\text { menta- } \\
\text { ção }\end{array}$ & $\mathbf{2 0 0 5}$ & $\mathbf{2 0 0 6}$ & $\mathbf{2 0 0 7}$ & $\mathbf{2 0 0 8}$ & $\mathbf{2 0 0 9}$ & $\mathbf{2 0 1 0}$ & $\mathbf{2 0 1 1}$ \\
\hline IDEB & 4,17 & 4,41 & 4,64 & 4,84 & 5,03 & 5,33 & 5,59 \\
\hline $\begin{array}{c}\text { Investi- } \\
\text { mento } \\
\text { Per Ca- } \\
\text { pita }\end{array}$ & 3843,57 & 4102,21 & 4952,46 & 5515,83 & 6151,77 & 6364,58 & 7237,05 \\
\hline
\end{tabular}

Fonte: Desenvolvido pelo pesquisador. Tesouro Nacional, 2011a, 2011b, 2011c, 2011d, 2011e, 2011f, 2011g; FGV-IBRE, 2009; INEP, 2011 e INEP, 2011f e 2011g.

Segue gráfico.

Gráfico o8: Médias do IDEB e do Investimento per capita para as séries iniciais de 2005 a 2011, segmentadas por ano.

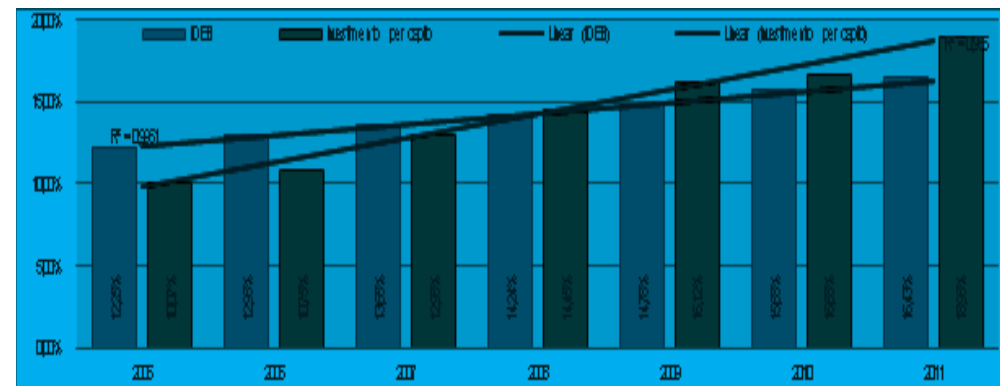

Fonte: Desenvolvido pelo pesquisador. Tesouro Nacional, 2011a, 2011b, 2011c, 2011d, 2011e, 2011f, 2011g; FGV-IBRE, 2009; INEP, 2011 e INEP, 2011f e 2011g.

Contrariando a análise segmentada por população, esta demonstra que as médias, tanto o IDEB, quanto o investimento per capita para os anos iniciais evoluíram de 2005 a 2011 com grande linearidade, mas com acelerações diferentes, o que pode caracterizar consequência, mas não provável. Enquanto o IDEB cresceu há uma taxa média de $0,7 \%$ os investimentos cresceram há uma taxa média de $1,48 \%$, pouco mais que o dobro. 
Tabela 07: Médias do IDEB e do Investimento per capita para as séries finais de 2005 a 2011, segmentadas por ano (em R\$).

\begin{tabular}{|c|c|c|c|c|c|c|c|}
\hline $\begin{array}{c}\text { Seg- } \\
\text { menta- } \\
\text { ção }\end{array}$ & $\mathbf{2 0 0 5}$ & $\mathbf{2 0 0 6}$ & $\mathbf{2 0 0 7}$ & $\mathbf{2 0 0 8}$ & $\mathbf{2 0 0 9}$ & $\mathbf{2 0 1 0}$ & $\mathbf{2 0 1 1}$ \\
\hline IDEB & 4,03 & 4,10 & 4,21 & 4,30 & 4,35 & 4,51 & 4,65 \\
\hline $\begin{array}{c}\text { Investi- } \\
\text { mento } \\
\text { Per Ca- } \\
\text { pita }\end{array}$ & 3194,34 & 3356,24 & 4074,32 & 4401,92 & 4841,57 & 5002,09 & 5472,75 \\
\hline
\end{tabular}

2011d, 2011e, 2011f, 2011g; FGV-IBRE, 2009; INEP, 2011 e INEP, 2011f e 2011g.

Segue gráfico.

Gráfico o9: Médias do IDEB e do Investimento per capita para as séries finais de 2005 a 2011, segmentadas por ano.

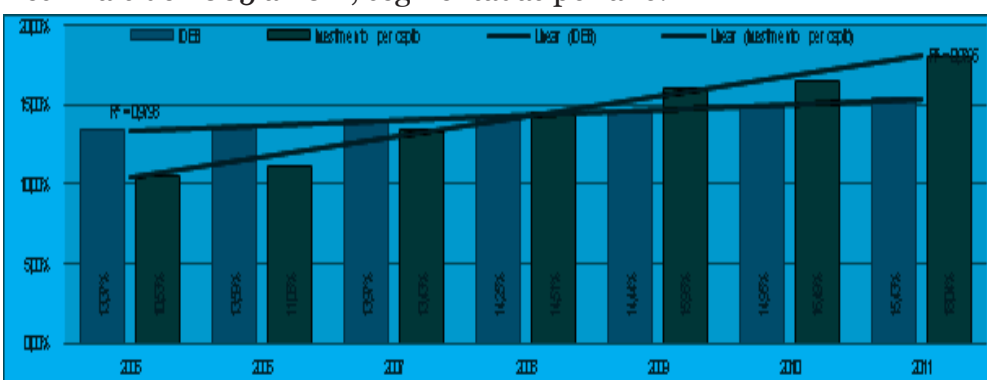

Fonte: Desenvolvido pelo pesquisador. Tesouro Nacional, 2011a, 2011b, 2011c, 2011d, 2011e, 2011f, 2011g; FGV-IBRE, 2009; INEP, 2011 e INEP, 2011f e 2011g.

Para os anos finais o cenário se repete com suas devidas peculiaridades, mas quanto à aceleração o IDEB cresceu há uma taxa média de 0,34\% (mais lento que nos anos iniciais) e os investimentos cresceram há uma taxa média de $1,25 \%$, quase cinco vezes mais rápido, o que representa que a ampliação dos gastos para obter resultados para as séries finais foi maior que a dos anos iniciais quando relacionadas com seus respectivos resultados do IDEB, apesar de os valores absolutos gastos ainda serem maiores nos anos iniciais.

\section{IDEB X INVESTIMENTO PER CAPITA SEG- MENTADO POR ASSOCIAÇÃO FECAM}

Esta análise buscou verificar se as associações, a partir das médias dos seus municípios integrantes, detêm uma correlação entre os dados de investimento frente ao índice de desempenho, neste ponto foi possível identificar severas irregularidades estatísticas ao passo que muitas obtiveram mesmos resultados com investimentos muito diferentes.

Tabela o8: Médias do IDEB e do Investimento per capita para as séries iniciais de 2005 a 2011, segmentadas por associação FECAM.

\begin{tabular}{|l|c|c|}
\hline \multicolumn{1}{|c|}{ Associação } & $\begin{array}{c}\text { Investimento per } \\
\text { capita }\end{array}$ & IDEB \\
\hline AMVALI & $\mathrm{R} \$ 3.790,54$ & 5,14 \\
\hline AMFRI & $\mathrm{R} \$ 3.850,20$ & 4,83 \\
\hline AMMVI & $\mathrm{R} \$ 3.873,50$ & 5,24 \\
\hline AMUNESC & $\mathrm{R} \$ 3.983,22$ & 4,92 \\
\hline AMPLANORTE & $\mathrm{R} \$ 4.280,85$ & 4,71 \\
\hline AMESC & $\mathrm{R} \$ 4.577,55$ & 4,66 \\
\hline
\end{tabular}


Tabela o8: Médias do IDEB e do Investimento per capita para as séries iniciais de 2005 a 2011, segmentadas por associação FECAM (continuação).

\begin{tabular}{|l|c|c|}
\hline \multicolumn{1}{|c|}{ Associação } & $\begin{array}{c}\text { Investimento per } \\
\text { capita }\end{array}$ & IDEB \\
\hline NÃO ASSOCIADO & $\mathrm{R} \$ 4.616,54$ & 5,04 \\
\hline GRANFPOLIS & $\mathrm{R} \$ 4.690,28$ & 4,82 \\
\hline AMURC & $\mathrm{R} \$ 4.981,33$ & 4,26 \\
\hline AMEOSC & $\mathrm{R} \$ 5 \cdot 107,53$ & 5,35 \\
\hline AMREC & $\mathrm{R} \$ 5 \cdot 174,04$ & 5,05 \\
\hline AMARP & $\mathrm{R} \$ 5 \cdot 558,54$ & 4,71 \\
\hline SANTA CATARINA & $\mathbf{R} \$ \mathbf{5 \cdot 5 9 7 , 9 6}$ & $\mathbf{4 , 9 0}$ \\
\hline AMAVI & $\mathrm{R} \$ 5.666,69$ & 4,99 \\
\hline AMPLASC & $\mathrm{R} \$ 5 \cdot 775,95$ & 4,52 \\
\hline AMNOROESTE & $\mathrm{R} \$ 5.807,08$ & 4,40 \\
\hline AMURES & $\mathrm{R} \$ 6.074,03$ & 4,28 \\
\hline AMMOC & $\mathrm{R} \$ 6.120,50$ & 5,11 \\
\hline AMAUC & $\mathrm{R} \$ 6.138,28$ & 5,30 \\
\hline AMUREL & $\mathrm{R} \$ 6.361,87$ & 4,68 \\
\hline AMERIOS & $\mathrm{R} \$ 6.531,55$ & 4,93 \\
\hline AMOSC & $\mathrm{R} \$ 7.088,41$ & 4,92 \\
\hline AMAI & $\mathrm{R} \$ 7.560,85$ & 5,01 \\
\hline FOnte: Desenvolvido pelo pesquisador. Tesouro $\mathrm{Nac10nal,} \mathrm{2011a,} \mathrm{2011b,} \mathrm{2011c,}$
\end{tabular}
2011d, 2011e, 2011f, 2011g; FGV-IBRE, 2009; INEP, 2011 e INEP, 2011f e 2011g.

A tabela anterior apresenta os dados médios para cada associação e já se pode visualizar que a AMAVALI investindo R \$ 3.790,54 per capita obteve um IDEB de 5,14, enquanto a AMAI investindo $\mathrm{R} \$ 7.560,85$ per capita obteve um IDEB de 5,01. A seguir gráfico percentual representativo.

Gráfico 1o: Médias do IDEB e do Investimento per capita para as séries iniciais de 2005 a 2011, segmentadas por associação FECAM.

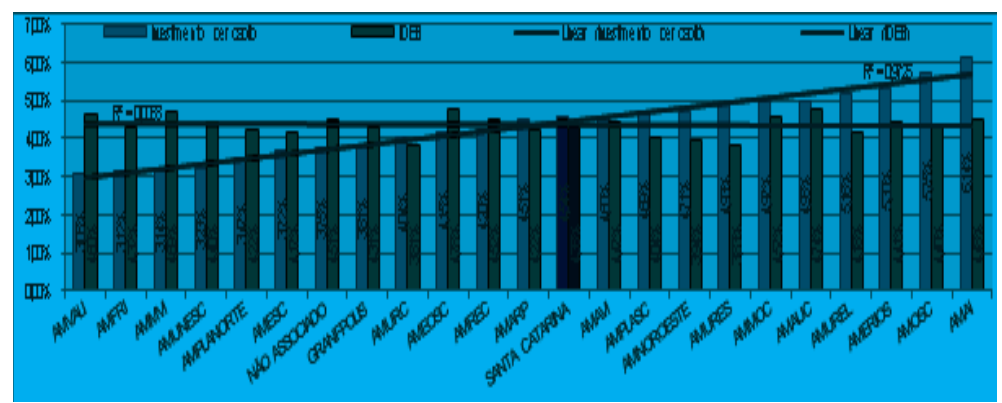

Fonte: Desenvolvido pelo pesquisador. Tesouro Nacional, 2011a, 2011b, 2011c, 2011d, 2011e, 2011f, 2011g; FGV-IBRE, 2009; INEP, 2011 e INEP, 2011f e 2011g.

O estudo revela que em segmentação por associações político-administrativas da FECAM não há correlação, o que significa que não se pode, neste caso, afirmar que os investimentos em educação foram proporcionais ao indicador de desempenho como o visto na segmentação por ano. A seguir a mesma análise sob os dados dos anos finais. 
Tabela o9: Médias do IDEB e do Investimento per capita para as séries finais de 2005 a 2011, segmentadas por associação FECAM.

\begin{tabular}{|c|c|c|}
\hline Associação & $\begin{array}{c}\text { Investimento per } \\
\text { capita }\end{array}$ & IDEB \\
\hline AMMVI & $\mathrm{R} \$ 3.599,22$ & 4,57 \\
\hline AMUNESC & $\mathrm{R} \$ 3.652,03$ & 4,44 \\
\hline AMARP & $\mathrm{R} \$ 3.700,04$ & 4,20 \\
\hline AMFRI & $\mathrm{R} \$ 3.732,45$ & 4,22 \\
\hline AMVALI & $\mathrm{R} \$ 3.736,69$ & 4,65 \\
\hline AMURC & $\mathrm{R} \$ 4.073,56$ & 3,75 \\
\hline AMPLANORTE & $\mathrm{R} \$ 4.111,93$ & 4,23 \\
\hline GRANFPOLIS & $\mathrm{R} \$ 4.251,82$ & 4,06 \\
\hline AMUREL & $\mathrm{R} \$ 4.458,53$ & 4,06 \\
\hline SANTA CATARINA & $\mathrm{R} \$ 4.461,55$ & 4,33 \\
\hline AMPLASC & $\mathrm{R} \$ 4.510,70$ & 4,17 \\
\hline AMAI & $\mathrm{R} \$ 4 \cdot 543,41$ & 4,51 \\
\hline AMMOC & $\mathrm{R} \$ 4.584,07$ & 4,76 \\
\hline AMESC & $\mathrm{R} \$ 4.589,08$ & 4,17 \\
\hline NÃO ASSOCIADO & $\mathrm{R} \$ 4.616,54$ & 4,13 \\
\hline AMAVI & $\mathrm{R} \$ 4.617,45$ & 4,31 \\
\hline AMERIOS & $\mathrm{R} \$ 4.727,19$ & 4,19 \\
\hline AMEOSC & $\mathrm{R} \$ 4.821,86$ & 4,86 \\
\hline AMNOROESTE & $\mathrm{R} \$ 5.084,22$ & 3,80 \\
\hline AMURES & $\mathrm{R} \$ 5 \cdot 333,52$ & 3,79 \\
\hline AMREC & $\mathrm{R} \$ 5 \cdot 345,18$ & 4,43 \\
\hline AMOSC & $\mathrm{R} \$ 5.671,36$ & 4,32 \\
\hline AMAUC & $\mathrm{R} \$ 5.698,49$ & 4,90 \\
\hline
\end{tabular}

2011d, 2011e, 2011f, 2011g; FGV-IBRE, 2009; INEP, 2011 e INEP, $2011 \mathrm{f} \mathrm{e} \mathrm{2011g.}$

Para as séries finais surgiram resultados tão irregulares quanto os das séries iniciais, segue gráfico percentual representativo.

Gráfico 11: Médias do IDEB e do Investimento per capita para as séries finais de 2005 a 2011, segmentadas por associação FECAM.

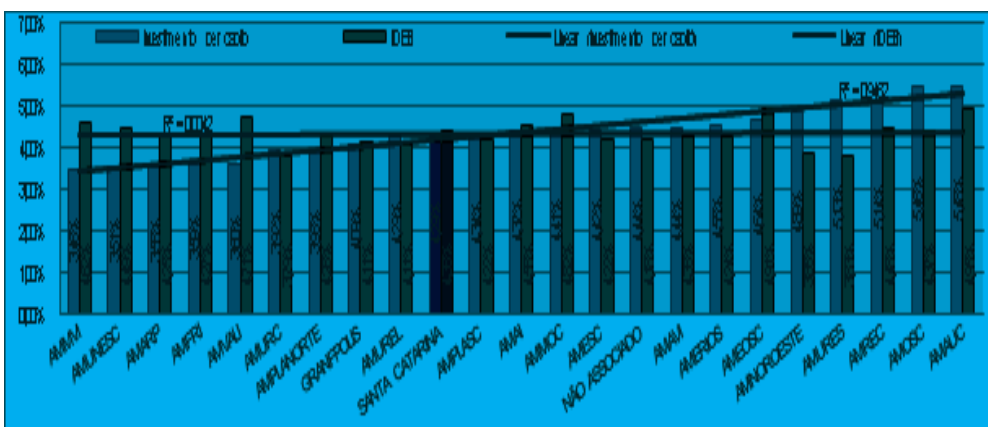

Fonte: Desenvolvido pelo pesquisador. Tesouro Nacional, 2011a, 2011b, 2011c, 2011d, 2011e, 2011f, 2011g; FGV-IBRE, 2009; INEP, 2011 e INEP, 2011f e 2011g.

Da mesma forma que para as séries iniciais, ao se buscar a linearidade para um tipo de valor o outro se dispersa, demonstrando não haver harmonia ou proporcionalidade entre eles, caracterizando assim, como já descrito, a ausência de correlação entre investimento e desempenho. 


\section{CUSTO DE CADA PONTO DO IDEB}

A análise a seguir tratou os pontos no IDEB como se pudessem ser comprados mediante investimento, para isso, fez-se necessário identificar o valor da unidade, ou seja, mensurar dentro dos dados Completos o valor de cada ponto no IDEB para cada município em cada ano, recordando que os valores passados foram trazidos ou atualizados ao Valor Presente do ano de 2011, podendo assim ser tratados de forma isonômica neste primeiro momento.

\section{CUSTO MÉDIO: TODOS OS MUNICÍPIOS SEG- MENTADOS POR ANO (2005 A 2011) PARA OS ANOS INICIAIS (1 ${ }^{\text {a }} 4^{\text {a }}$ SÉRIES).}

O aumento do custo médio ao longo dos anos demonstra que em média os municípios de Santa Catarina estão gastando, a cada ano, mais recursos por ponto. Esse fenômeno ocorre quando os investimentos aumentam, mas os resultados se mantêm ou os investimentos se mantêm, no entanto os resultados reduzem. Os resultados do valor por ponto no IDEB foram os seguintes: $2005 \mathrm{R} \$ 949,74$; $2007 \mathrm{R}$ \$ 1.096,59; $2009 \mathrm{R}$ \$ 1.244,19 e $2011 \mathrm{R}$ \$ 1.322,20.

Apesar de crescente o valor de cada ponto do IDEB ao passar do tempo, pode-se perceber uma desaceleração à medida que o tempo passa, onde o aumento de 2005 para 2007 era de 15,46\%, já de 2007 para 2009 ficou em $13,46 \%$, reduzindo significativamente de 2009 para 2011 quando atingiu $6,27 \%$ de aumento, ou seja, o custo de cada ponto no IDEB tendeu à estabilidade no período estudado.

CUSTO MÉDIO: TODOS OS MUNICÍPIOS SEGMENTADOS POR ANO (2005 A 2011) PARA OS ANOS FINAIS (5 ${ }^{\mathrm{a}}$ A $8^{\mathrm{a}}$ SÉRIES).

Tal como nas Médias dos Valores por Ponto IDEB ( $1^{\mathrm{a}}$ a $4^{\mathrm{a}}$ séries), aqui nas médias de $5^{\mathrm{a}}$ a $8^{\mathrm{a}}$ séries também se percebe aumento similar no custo de cada ponto.

Os resultados do valor por ponto no IDEB foram os seguintes: 2005 R 805,15; 2007 R 1.011,30; 2009 R \$ $1.144,24$ e $2011 \mathrm{R} \$ 1.201,81$.

Com o passar dos anos o a média do IDEB e a média dos investimentos per capita aumentaram, mas de maneira desproporcional, caracterizando um pequeno aumento da eficiência no uso dos recursos, pois se desacelerou um pouco o aumento do custo por ponto do IDEB.

Tanto para séries iniciais quanto finais o custo de cada ponto do IDEB tem aumentado, mas com tendência à estabilização. Percebe-se uma desaceleração, quando o aumento de 2005 para 2007 era de 25,60\%, já de 2007 para 2009 ficou em 13,15\%, reduzindo para menos da metade de 2009 para 2011 ao atingir 5,03\% de aumento, ou seja, o custo de cada ponto no IDEB tendeu à estabilidade no período estudado tanto para as séries iniciais quanto para as finais. 
Existem dois fatores que também podem ter gerado esta desaceleração, um reside na inadequação da escolha do IGP-DI, ou seja, este índice pode influenciar diretamente nesta análise; o segundo fator se relaciona com a completude dos dados obtidos que para as séries iniciais foi de 64,16\% em 2005 para 85,32\% de completude em 2011, enquanto as séries finais migraram de 31,06\% em 2005 para $41,30 \%$ em 2011. Esse fato pode influenciar na estabilização ao passo que contempla maior volume de dados.

\section{CUSTO MÉDIO: 20\% DOS MUNICÍPIOS COM MAIOR E MENOR DESEMPENHO NO IDEB.}

Seguindo os princípios de Pareto, optou-se por isolar os vinte por cento maiores resultados do IDEB dentre os dados Completos a fim de identificar se os municípios que conseguem as melhores notas no IDEB gastam mais recurso por ponto. Nesta análise pode o mesmo município, aparecer até sete vezes, pois os dados anuais se encontram em equivalência e foram utilizados todos os dados disponíveis em todos os anos para todos os municípios, limitando-se a completude dos dados. Coube ainda a ampliação do quantitativo para além dos $20 \%$ quando em uma sequencia o município subsequente possuir a mesma nota do último, procedendo a inclusão até que se encontre um município subsequente com nota do IDEB maior que o último selecionado.

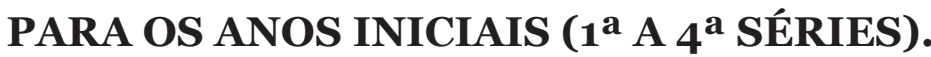

Total de dados completos disponíveis: 1.548 x 20\% = 309,6 e ampliado para 338 pela existência de mesma nota no município/ano subsequente em cada um dos anos 2005 a 2011. A seguir a tabela com a apresentação dos dados utilizados.

Tabela 10: Identificação do número de municípios representantes dos 20\% MAIORES e MENORES resultados do IDEB para as séries iniciais nos anos de 2005 a 2011.

\begin{tabular}{|c|c|c|c|c|c|c|c|c|}
\hline & $\mathbf{2 0 0 5}$ & $\mathbf{2 0 0 6}$ & $\mathbf{2 0 0 7}$ & $\mathbf{2 0 0 8}$ & $\mathbf{2 0 0 9}$ & $\mathbf{2 0 1 0}$ & $\mathbf{2 0 1 1}$ & $\begin{array}{c}\text { TO- } \\
\text { TAIS }\end{array}$ \\
\hline $\begin{array}{c}\text { Total por } \\
\text { ano }\end{array}$ & 188 & 184 & 234 & 226 & 241 & 225 & 250 & $\mathbf{1 5 4 8}$ \\
\hline $\begin{array}{c}\text { Qt. Equiva- } \\
\text { lente a 20\% }\end{array}$ & 37,6 & 36,8 & 46,8 & 45,2 & 48,2 & 45 & 50 & $\mathbf{3 0 9 , 6}$ \\
\hline $\begin{array}{c}\text { Qt. Meno- } \\
\text { res Result. } \\
\text { IDEB }\end{array}$ & 39 & 42 & 53 & 50 & 53 & 45 & 56 & $\mathbf{3 3 8}$ \\
\hline $\begin{array}{c}\text { Qt. Maio- } \\
\text { res Result. } \\
\text { IDEB }\end{array}$ & 41 & 38 & 51 & 46 & 52 & 50 & 60 & $\mathbf{3 3 8}$ \\
\hline
\end{tabular}

Fonte: Desenvolvido pelo pesquisador. INEP, 2011f e 2011g.

Dos 293 municípios, nem todos possuíam dados suficientes para participar desta análise, mas ainda com significativa representatividade ainda é possível obter algumas conclusões, vistas a seguir logo após a apresentação do resultado deste fracionamento: 
Tabela 11: Médias anuais do Investimento Per Capita e do IDEB das séries iniciais dos 20\% com maiores e menores resultados no IDEB nos anos de 2005 a 2011.

\begin{tabular}{|c|c|c|c|c|c|c|c|c|}
\hline \multirow{2}{*}{$\begin{array}{l}\text { Os 2o\% } \\
\text { MENO- } \\
\text { RES }\end{array}$} & $\begin{array}{c}\text { Inv. Per } \\
\text { Capita }\end{array}$ & $4.059,15$ & $4.291,74$ & $5.183,34$ & $5 \cdot 284,36$ & $5.877,71$ & $5 \cdot 918,40$ & $7 \cdot 589,47$ \\
\hline & $\begin{array}{l}\text { IDEB } \\
\text { Médio }\end{array}$ & 3,49 & 3,81 & 3,92 & 4,17 & 4,23 & 4,52 & 4,66 \\
\hline \multirow{2}{*}{$\begin{array}{l}\text { Os 2o\% } \\
\text { MAIO- } \\
\text { RES }\end{array}$} & $\begin{array}{c}\text { Inv. Per } \\
\text { Capita }\end{array}$ & $3 \cdot 747,66$ & $4.040,60$ & $5.285,46$ & $5 \cdot 942,40$ & $6.619,71$ & $6.663,66$ & $6.503,81$ \\
\hline & $\begin{array}{l}\text { IDEB } \\
\text { Médio }\end{array}$ & 4,87 & 5,10 & 5,47 & 5,62 & 5,87 & 6,08 & 6,44 \\
\hline
\end{tabular}

Fonte: Desenvolvido pelo pesquisador. INEP, 2011f e 2011g.

A análise a seguir apresenta a diferença percentual a cada ano, traçando um comparativo entre a evolução das médias dos 20\% menores com as médias dos 20\% maiores:

Gráfico 14: Diferença percentual anual entre os 20\% menores frente os 20\% maiores resultados do IDEB das médias de Investimento Per Capita e IDEB para os anos de 2005 a 2011 nas séries iniciais.

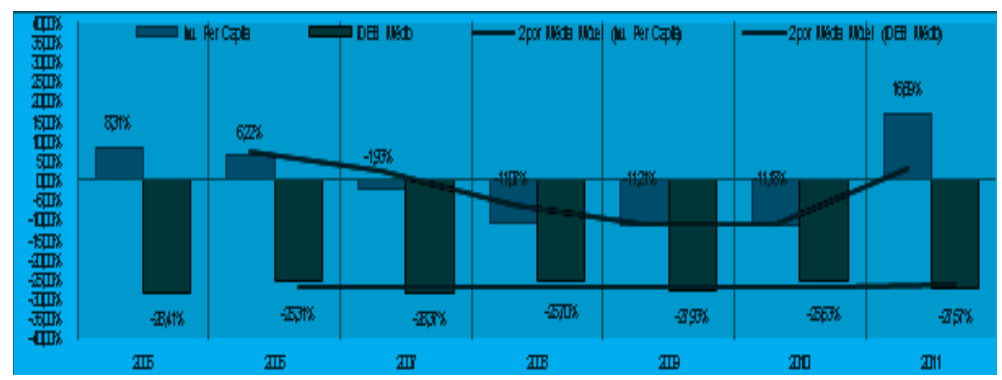

Fonte: Desenvolvido pelo pesquisador. INEP, 2011f e 2011g.

Este gráfico demonstra que a média dos investimentos por aluno dos 20\% MENORES resultados do IDEB em 2005 e 2006 ficou em torno de 7,3\% a mais que os $20 \%$ MAIORES, enquanto a diferença do resultado médio do IDEB ficou em torno de 26,9\% menor. Em 2008, 2009 e 2010 a diferença nos investimentos se inverteu e os $20 \%$ MENORES investiram em torno de $11,2 \%$ a mais que os 20\% MAIORES, no entanto o IDEB médio manteve-se com uma significativa diferença de $26,4 \%$ a mais para os $20 \%$ MAIORES, demonstrando que não houve correlação significativa, pois do contrário esta diferença deveria acompanhar a outra, em termos proporcionais, à medida que o investimento aumentasse para demonstrar que o aumento de investimentos impactaria na redução da diferença do IDEB. Em 2011 a diferença no investimento aumentou drasticamente chegando ao maior índice do período estudado, com os 20\% MENORES investindo 16,69\% a mais que os 20\% MAIORES e a diferença no IDEB alcançando $27,57 \%$ a menos que os $20 \%$ MAIORES, mantendo-as ainda muito próximo da média da diferença entre os 7 (sete) anos analisados e novamente demonstrando não haver relação direta entre o investimento per capita e o IDEB.

Faz necessário lembra que para esta análise os dados de natureza financeira e demográfica utilizados encontram-se integrais, mas os relacionados ao IDEB existem apenas para os anos de 2005, 2007, 2008, 2009 e 2011, enquanto 
os de 2006, 2008 e 2010, evidenciados no gráfico com uma borda amarela, resultam da média intermediária entre os anos anteriores e posteriores, o que pode ter causado incompletude em algum conjunto por depender de dois valores para sua existência. Esse fato é de relevância, pois pode ser o causador da redução da diferença para os anos calculados, mas não interfere de modo significativo no contexto analisado.

\section{PARA OS ANOS INICIAIS (5 ${ }^{\mathrm{a}}$ A $9^{\text {a }}$ SÉRIES).}

Apesar da incompletude de dados para as séries finais, conforme tabela a seguir:

Tabela 12: Identificação do número de municípios representantes dos 20\% MAIORES e MENORES resultados do IDEB para as séries finais nos anos de 2005 a 2011.

\begin{tabular}{|c|c|c|c|c|c|c|c|c|}
\hline & $\mathbf{2 0 0 5}$ & $\mathbf{2 0 0 6}$ & $\mathbf{2 0 0 7}$ & $\mathbf{2 0 0 8}$ & $\mathbf{2 0 0 9}$ & $\mathbf{2 0 1 0}$ & $\mathbf{2 0 1 1}$ & $\begin{array}{c}\text { TO- } \\
\text { TAIS }\end{array}$ \\
\hline $\begin{array}{c}\text { Total por } \\
\text { ano }\end{array}$ & 91 & 90 & 123 & 118 & 125 & 119 & 121 & 787 \\
\hline $\begin{array}{c}\text { Qt. Equiva- } \\
\text { lente a 2o\% }\end{array}$ & 18,2 & 18 & 24,6 & 23,6 & 25 & 23,8 & 24,2 & 157,4 \\
\hline $\begin{array}{c}\text { Qt. Menores } \\
\text { Result. IDEB }\end{array}$ & 23 & 21 & 33 & 26 & 25 & 26 & 24 & 178 \\
\hline $\begin{array}{c}\text { Qt. Maiores } \\
\text { Result. IDEB }\end{array}$ & 19 & 23 & 26 & 26 & 27 & 26 & 27 & 174 \\
\hline
\end{tabular}

Fonte: Desenvolvido pelo pesquisador. INEP, 2011f e 2011g.

O ideal seria se houvessem todos os dados de todos os municípios por ano (293 x 7), mas em nenhum dos anos encontra-se pelo menos a metade $(146,5)$ dos municípios com dados completos, mas ainda se configura válida a análise ao passo que o total de Investimentos Públicos Diretos em educação para as séries finais (de $5^{\mathrm{a}}$ a $8^{\mathrm{a}}$ séries) para os anos de 2005 a 2011 foram de $\mathrm{R} \$ 4.411 .274 .174,82$ e o valor total constante nos dados completos é de $\mathrm{R} \$$ 4.028.353.455,14, que representa $91,32 \%$ do valor total investido.

Tabela 13: Médias anuais do Investimento Per Capita e do IDEB das séries finais dos 20\% com maiores e menores resultados no IDEB nos anos de 2005 a 2011.

\begin{tabular}{|c|c|c|c|c|c|c|c|c|}
\hline $\begin{array}{c}\text { Os } \\
\mathbf{2 0 \%}\end{array}$ & $\begin{array}{c}\text { Inv. } \\
\text { Per } \\
\text { Capita }\end{array}$ & $\begin{array}{c}\mathrm{R} \$ \\
3093,81\end{array}$ & $\begin{array}{c}\mathrm{R} \$ \\
3369,62\end{array}$ & $\begin{array}{c}\mathrm{R} \$ \\
3971,84\end{array}$ & $\begin{array}{c}\mathrm{R} \$ \\
4692,70\end{array}$ & $\begin{array}{c}\mathrm{R} \$ \\
4855,07\end{array}$ & $\begin{array}{c}\mathrm{R} \$ \\
5050,22\end{array}$ & $\begin{array}{c}\mathrm{R} \$ \\
5738,54\end{array}$ \\
\hline $\begin{array}{l}\text { ME- } \\
\text { NO- } \\
\text { RES }\end{array}$ & $\begin{array}{l}\text { IDEB } \\
\text { Médio }\end{array}$ & 3,40 & 3,51 & 3,54 & 3,58 & 3,51 & 3,76 & 3,83 \\
\hline $\begin{array}{c}\text { Os } \\
\mathbf{2 0 \%}\end{array}$ & $\begin{array}{c}\text { Inv. } \\
\text { Per } \\
\text { Capita }\end{array}$ & $\begin{array}{c}\mathrm{R} \$ \\
3334,45\end{array}$ & $\begin{array}{c}\mathrm{R} \$ \\
3528,37\end{array}$ & $\begin{array}{c}\mathrm{R} \$ \\
5098,82\end{array}$ & $\begin{array}{c}\mathrm{R} \$ \\
4541,42\end{array}$ & $\begin{array}{c}\mathrm{R} \$ \\
5120,55\end{array}$ & $\begin{array}{c}\mathrm{R} \$ \\
5159,45\end{array}$ & $\begin{array}{c}\mathrm{R} \$ \\
5417,99\end{array}$ \\
\hline $\begin{array}{l}\text { MAIO- } \\
\text { RES }\end{array}$ & $\begin{array}{l}\text { IDEB } \\
\text { Médio }\end{array}$ & 4,70 & 4,67 & 5,03 & 5,08 & 5,24 & 5,36 & 5,52 \\
\hline
\end{tabular}

Fonte: Desenvolvido pelo pesquisador. INEP, 2011f e 2011g.

A análise a seguir apresenta a diferença percentual a cada ano, traçando um comparativo entre a evolução das médias dos 20\% menores com as médias dos 20\% maiores, agora para os anos finais: 
Gráfico 15: Diferença percentual anual entre os 20\% menores frente os 20\% maiores resultados do IDEB das médias de Investimento Per Capita e IDEB para os anos de 2005 a 2011 nas séries finais.

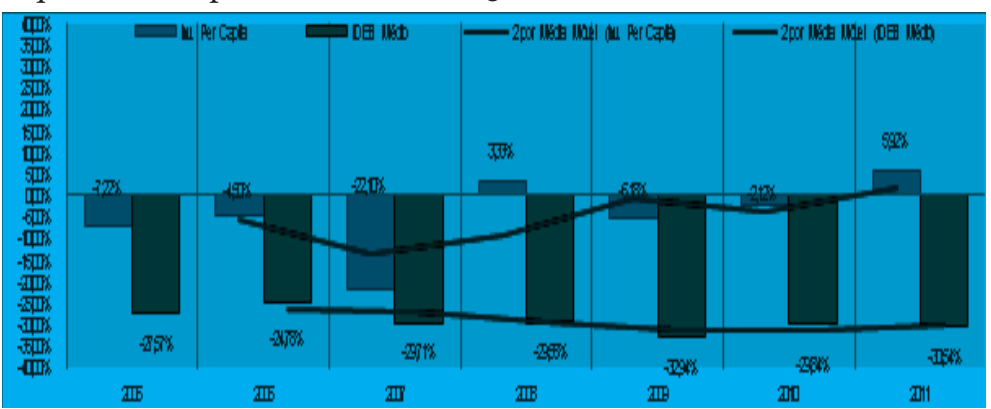

Fonte: Desenvolvido pelo pesquisador. INEP, 2011f e 2011g.

Este gráfico demonstra que a média dos investimentos por aluno dos 20\% MENORES resultados do IDEB, com exceção de 2007 , ficou abaixo de $8 \%$ para os demais anos estudados, no entanto a diferença em relação ao IDEB manteve-se alta e sem sofrer influência direta do investimento per capito demonstrando que para as séries finais, nesta análise, também não houve correlação.

\section{CUSTO MÉDIO: DOS MUNICÍPIOS MAIS E MENOS POPULOSOS.}

Para segmentação dos municípios de acordo com a população, adotou-se a regra de segmentação por categorias mais fracionadas em números baixos em função da natureza demográfica de Santa Catarina.

Gráfico 16: Custo médio por ponto do IDEB segmentado pelo contingente populacional dos Municípios de Santa Catarina para nos anos de 2005 a 2011 para $1^{\mathrm{a}}$ a $4^{\mathrm{a}}$ séries.

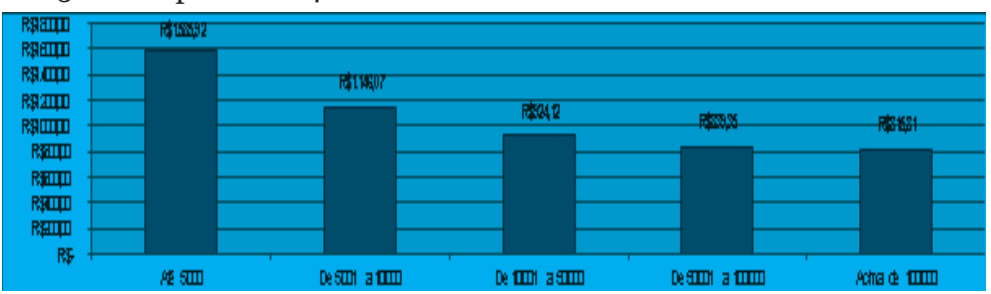

Fonte: Desenvolvido pelo pesquisador. Tesouro Nacional, 2011a, 2011b, 2011c, 2011d, 2011e, 2011f, 2011g; FGV-IBRE, 2009; INEP, 2011d; FECAM, 2013c e INEP, 2011f e 2011g.

Notável diferença surge neste comparativo para as séries iniciais, demonstrando que o custo para obtenção de bom desempenho é maior em municípios com menor população, chegando à diferença de $49 \%$ entre cidades de até 5.000 habitantes frente às acima de 100.000 habitantes; as diferenças desaceleram na medida em que o quantitativo populacional se amplia, seguindo na ordem: $-28 \%,-19 \%$, $-9 \%$ e $-3 \%$. 
Gráfico 17: Custo médio por ponto do IDEB segmentado pelo contingente populacional dos Municípios de Santa Catarina para nos anos de 2005 a 2011 para $5^{\mathrm{a}}$ a $8^{\mathrm{a}}$ séries.

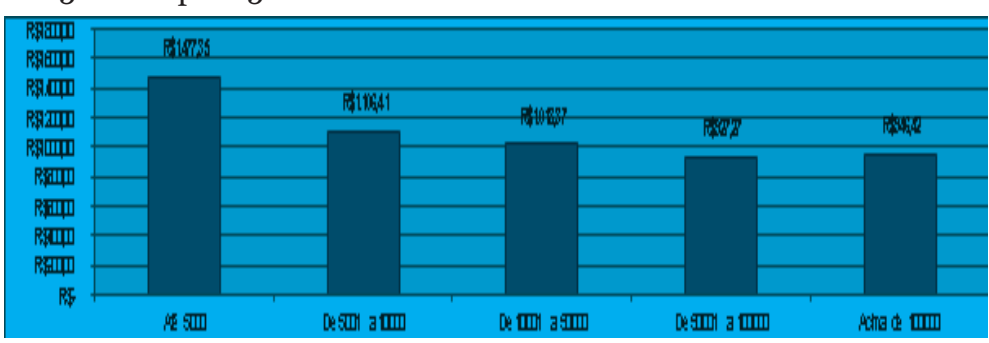

Fonte: Desenvolvido pelo pesquisador. Tesouro Nacional, 2011a, 2011b, 2011c, 2011d, 2011e, 2011f, 2011g; FGV-IBRE, 2009; INEP, 2011d; FECAM, 2013c e INEP, 2011f e 2011g.

Para as séries finais a diferença persiste de forma quase que tão intensa quanto para as séries iniciais, chegando à diferença de $36 \%$ entre cidades de até 5.000 habitantes frente às acima de 100.000 habitantes; as diferenças desaceleram à medida em que o quantitativo populacional se amplia, seguindo na ordem: $-25 \%,-8 \%,-9 \%$ e $-2 \%$.

\section{CUSTO MÉDIO: ASSOCIAÇÕES FECAM.}

Seguindo a mesma dinâmica da segmentação populacional este segmenta os valores conforme a divisão político-administrativa apresentada pela FECAM, isolando para as séries iniciais e séries finais, estabelecendo também um divisor baseado na média do estado de Santa Catarina.

Gráfico 18: Custo Médio de cada ponto IDEB para séries iniciais $\left(1^{\mathrm{a}}\right.$ a $4^{\mathrm{a}}$ séries) para as associações FECAM de 2005 a 2011.

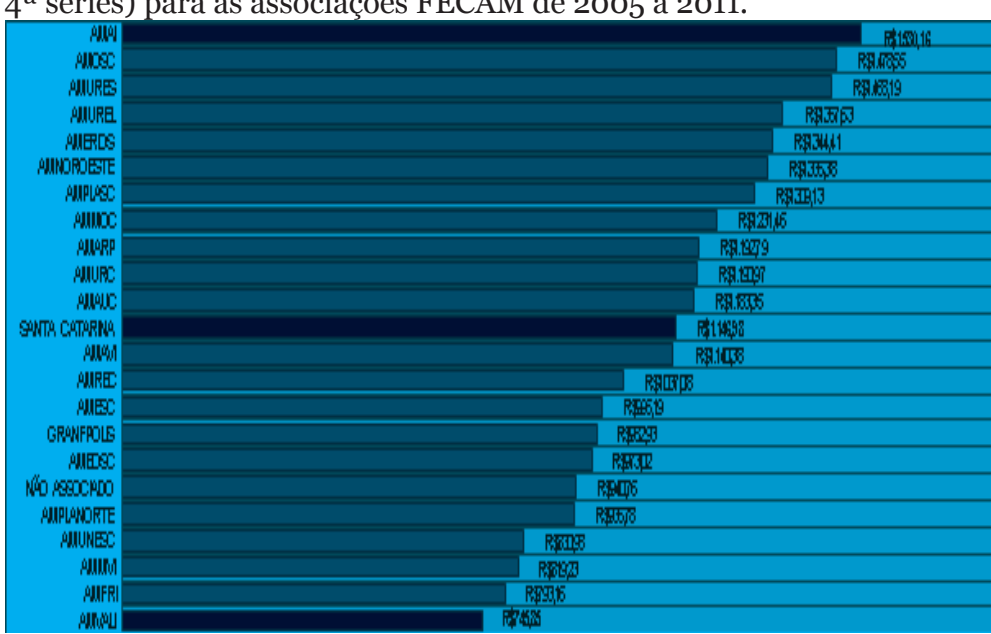

Fonte: Desenvolvido pelo pesquisador. Tesouro Nacional, 2011a, 2011b, 2011c, 2011d, 2011e, 2011f, 2011g; FGV-IBRE, 2009; INEP, 2011d; FECAM, 2013c e INEP, 2011f e 2011g.

O estabelecimento de um indicador global ajudou a compreender o distanciamento de algumas associações em relação ao que deveria ser a normalidade, ora obtida na condição global (Estado de Santa Catarina), encontra-se um diferença de valor 53,78\% mais baixo para AMVALI em relação à Santa Catarina, o que significa que para o Estado, em termos globais, o custo de cada ponto no IDEB para as séries iniciais é mais que o dobro. Já em relação a AMAI a diferença é menor, mas ainda significativa, chegando a 25,04\% maior para AMAI em relação ao estado. 
Gráfico 19: Custo Médio de cada ponto IDEB para séries finais $\left(5^{\mathrm{a}}\right.$ a $8^{\mathrm{a}}$ séries) para as associações FECAM de 2005 a 2011.

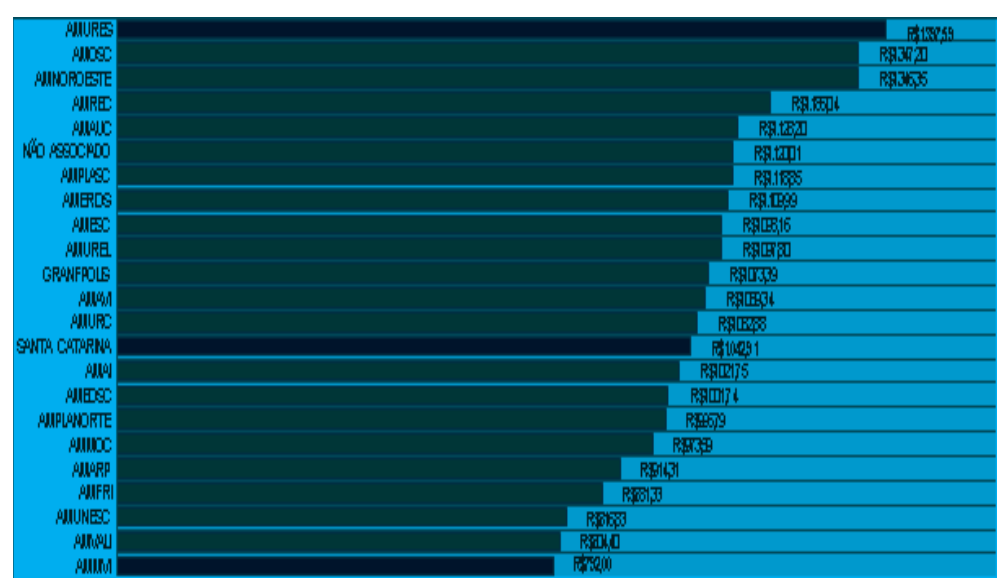

Fonte: Desenvolvido pelo pesquisador. Tesouro Nacional, 2011a, 2011b, 2011c, 2011d, 2011e, 2011f, 2011g; FGV-IBRE, 2009; INEP, 2011d; FECAM, 2013c e INEP, 2011f e 2011g.

Para as séries finais o custo por ponto das associações fica mais próximo do valor apresentado pelo estado, ficando 31,68\% menor para AMMVI em relação ao estado de 25,38\% a maior para AMURES em relação ao estado, seguindo certa estabilidade na extremidade mais cara, apesar de AMURES, AMOSC e AMNOROESTE apresentarem um salto em relação à antecessora AMREC.

\section{ENTENDIMENTO FINAL}

Apesar da complexidade subjetiva envolvida no processo de ensino e entendendo não se pode meramente aplicar valores esperando desempenho, pode-se observar que rever dados estatísticos passados auxilia na compreensão de como toda essa subjetividade no gerenciamento de um recurso reflete no indicador de desempenho e a partir disto traçar comparativos para identificação de municípios que obtiveram melhores resultados investindo menos, servindo eles, em uma futura pesquisa qualitativa, de modelo para os que obtiveram resultados negativos. O estudo não permitiu ao pesquisador traçar extensos comentários sobre detalhes em cada cruzamento de dados, buscou-se aqui efetuar o máximo levantamento possível a fim de dar ao mundo científico bases mais sólidas para novos olhares e novas interpretações sobre os atuais paradigmas. Quanto aos resultados foi possível verificar que apenas em análise relacionada ao tempo houve correlação significativa entre investimento per capita e resultados do IDEB, no entanto todos os outros fracionamentos e segmentações demonstraram que o investimento não gera efeito direto sobre os resultados do IDEB. Considerando que os dados do IDEB têm sofrido uma crescente nos últimos anos e tal como os valores disponibilizados para o Ensino Fundamental, pode ter ocorrido uma coincidência estatística, mas por hora representa uma mera hipótese. Outro fator que possa ter influenciado na existência desta correlação pode residir no índice de correção escolhido, o IGP-DI, que apesar de refle- 
tir as variações dos investimentos públicos, possa ter gerado uma distorção na equivalência dos dados, mas também representa outra hipótese.

Na comparação entre os municípios a partir da segmentação baseada no quantitativo populacional foi encontrada uma significativa diferença à medida que o tamanho variava, demonstrando que cidades com menos habitantes gastaram mais recursos por aluno para obter pontos no IDEB, acredita-se que isso possa ser em função da necessidade de transporte rural e pouca oferta de insumos, o que pode torná-los mais caros. Mesmo com este elevado valor de investimento, os municípios menos populosos ainda detêm as melhores médias do IDEB. O fator monetário compõe, mas não é o responsável direto pelo desempenho mensurado pelo IDEB, acredita-se que o fator humano, na gestão dos recursos, seja o grande responsável pelo sucesso ou fracasso desse indicador.

\section{REFERÊNCIAS}

BRASIL. Lei no 9.394, de 20 de dezembro de 1996. Estabelece as diretrizes e bases da educação nacional. Palácio do Planalto, Brasília, DF. Disponível em: http://www. planalto.gov.br/ccivil_03/leis/l9394.htm. Acesso em 22/06/2013.

FECAM. 2013c. Associações Municipais. http:// www.fecam.org.br/associacoes/index.php. Acesso em: 07/07/2013.

FGV-IBRE, 2009. FGVDados: Visualização dos resultados da consulta. http://www14.fgv.br/novo_fgvdados/visualizaconsulta.aspx. Acesso em 07/11/2013.

FREIRE, Paulo. Pedagogia da Autonomia: saberes necessários à prática educativa. São Paulo: Paz e Terra, 2003.

INEP. 2011d. Sistema de Consulta a Matrícula do Censo Escolar - 1997/2013: Resultados Preliminares do Censo Escolar (2005 a 2011), Santa Catarina. http://portal.inep.gov.br/basica-censo-escolar-matricula. Acesso em: 17/06/2013.

INEP. 2011f. Ensino Fundamental Regular - Anos Iniciais. http://download.inep.gov.br/educacao_basica/ portal_ideb/planilhas_para_download/divulgacao-anos-iniciais-municipios-2011.xls. Acesso em 21/o6/2013.

INEP. 2011g. Ensino Fundamental Regular - Anos Finais. http://download.inep.gov.br/educacao_basica/ portal_ideb/planilhas_para_download/divulgacao-anos-finais-municipios-2011.xls. Acesso em 21/06/2013. 
INEP. 2011j. Tabela 1.2 - Histórico da Estimativa do Percentual do Investimento Público Direto em Educação em Relação ao Produto Interno Bruto (PIB), por Nível de Ensino - Brasil 2000 - 2011. Inep/MEC - Tabela elaborada pela DEED/Inep. http://download.inep.gov.br/download/estatisticas/gastos_educacao/docs/indicadores_financeiros/percentual_investimento_diretol_PIB.xls. Acesso em 17/06/2013.

TESOURO NACIONAL. 2013b. Finanças do Brasil Dados Contábeis dos Municípios - 2010. http:// www3.tesouro.gov.br/estados_municipios/financas/Finbra2010v13out.zip. Acesso em: 31/10/2013.

TESOURO NACIONAL. 2013c. Finanças do Brasil Dados Contábeis dos Municípios - 2009. http:// www3.tesouro.gov.br/estados_municipios/financas/Finbra2009v1.zip. Acesso em: 31/10/2013.

TESOURO NACIONAL. 2013d. Finanças do Brasil Dados Contábeis dos Municípios - 2008. http:// www3.tesouro.gov.br/estados_municipios/financas/Finbra2008v1.zip. Acesso em: 31/10/2013.

TESOURO NACIONAL. 2013e. Finanças do Brasil Dados Contábeis dos Municípios - 2007. http:// www3.tesouro.gov.br/estados_municipios/financas/Finbra2007v13out.zip. Acesso em: 31/10/2013.

TESOURO NACIONAL. 2013f. Finanças do Brasil - Dados Contábeis dos Municípios - 2006. https://www. tesouro.fazenda.gov.br/images/arquivos/artigos/Finbra2006exto8mai.zip. Acesso em: 31/10/2013.

TESOURO NACIONAL. 2013g. Finanças do Brasil Dados Contábeis dos Municípios - 2005. https:// www.tesouro.fazenda.gov.br/images/arquivos/artigos/ Finbra2005vo809.zip. Acesso em: 31/10/2013. 